\title{
ANATOMIA DO LENHO DE MIMOSA FLOCCULOSA BURKART ${ }^{1}$
}

\author{
ANE CAROLINE DA SILVA PEREIRA ${ }^{2}$ ANELISE MARTA SIEGLOCH ${ }^{3}$ \\ JOSÉ NEWTON CARDOSO MARCHIORI ${ }^{4}$
}

\section{RESUMO}

O lenho de Mimosa flocculosa Burkart é anatomicamente descrito, com base em material procedente de Colombo, Paraná. Foram observados os seguintes caracteres: placas de perfuração simples; elementos vasculares curtos; pontoações intervasculares alternas, ornamentadas; parênquima paratraqueal; raios heterogêneos; fibras libriformes; e ausência de estratificação.

Palavras-chave: Anatomia da madeira, Mimosa flocculosa, Fabaceae.

\section{ABSTRACT}

[Wood anatomy of Mimosa flocculosa Burkart].

The wood of Mimosa flocculosa Burkart is anatomically described, based on material from the municipality of Colombo, Paraná State (Brazil). The following features were observed: simple perforation plates; short vascular elements; alternate vestured pits; paratracheal parenchyma; heterogeneous rays; libriform fibers; and non storied structure.

Key words: Wood anatomy, Mimosa flocculosa, Fabaceae.

\section{INTRODUÇÃO}

Com cerca de 650 gêneros e aproximadamente 19.000 espécies, a família Fabaceae é uma das maiores das Angiospermas e, também, uma das mais importantes sob do ponto de vista econômico, distribuindo-se em todas as partes do mundo (Souza \& Lorenzi, 2012), com exceção das regiões árticas e antárticas (Marchiori, 2007). Com cerca de 500 espécies (Judd et al., 2009), o gênero Mimosa é um dos mais numerosos da família, tanto pela abundância de espécies em países de clima quente, como por ter dado nome a um dos sub-grupos da família (Burkart, 1979).

1 Recebido para publicação em 24/07/2013 e aceito para publicação em 04/09/2013.

2 Acadêmica do curso de Engenheira Florestal. Bolsista de Iniciação Científica (PIBIC - CNPQ). Universidade Federal de Santa Maria. Santa Maria, RS, Brasil. aneh.caroline@hotmail.com

3 Mestranda do Programa de Pós-Graduação em Engenheira Florestal. Bolsista - CAPES. Universidade Federal de Santa Maria. Santa Maria, RS, Brasil.

4 Engenheiro Florestal, Dr. Bolsista de Produtividade em Pesquisa (CNPq - Brasil). Professor Titular do Departamento de Ciências Florestais, Universidade Federal de Santa Maria. Santa Maria, RS, Brasil.
Conhecida pelo nome de bracatinga-do-campo, bracatinga-da-branca, bracatinga-rósea, jurema e vassoura, Mimosa flocculosa Burkart é arvoreta perenifólia de até $5 \mathrm{~m}$ de altura, de folhas bipinadas, com folíolos opostos e abundantes flores róseas, em inflorescências terminais de até $30 \mathrm{~cm}$ (Carvalho, 2003). Barneby (1991) menciona os meses de setembro a maio como período de floração.

Com mais de 80 espécies nativas no sul do Brasil, são relativamente escassas as espécies de Mimosa para as quais foram descritos os caracteres microscópicos do lenho, salientandose, neste aspecto: Mimosa daleoides (Marchiori, 1882); M. cruenta (Marchiori, 1985); M. bimucronata (Marchiori, 1980, 1993); M. eriocarpa (Carnieletto \& Marchiori, 1993): $M$. sparsa (Maccari \& Marchiori, 1994): M. scabrella (Marchiori, 1980, 1995); M. berroi (Marchiori, 1996a); M. incana (Marchiori, 1996b); M. uruguensis (Marchiori (1996c); M. pilulifera (Marchiori \& Muñiz, 1997a); M. trachycarpa (Marchiori \& Muñiz, 1997b); e M. micropteris (Pereira, et al., 2013).

$O$ presente estudo visa descrever a estrutura do lenho de Mimosa flocculosa Burkart, espé- 
cie até o momento desconhecida sob o ponto de vista anatômico, bem como reconhecer caracteres anatômicos de valor taxonômico em seu lenho.

\section{MATERIAL E MÉTODOS}

O material em estudo consiste de uma amostra de madeira e respectivo material botânico, conservados na Xiloteca e Herbário do Departamento de Ciências Florestais da Universidade Federal de Santa Maria (HDCF) sob o número 3198. Na etiqueta de herbário, constam os seguintes dados: Colombo, PR, Marchiori, J. N. C., 10-11-1988.

Para a confecção de lâminas histológicas foram extraídos três corpos de prova $(1 \times 2 \times 3 \mathrm{~cm})$ da parte mais externa do lenho, próxima ao câmbio, orientados para obtenção de cortes nos planos transversal, longitudinal radial e longitudinal tangencial. Outro bloquinho foi também retirado, com vistas à maceração.

O preparo de lâminas histológicas seguiu a metodologia descrita em Burger \& Richter (1991). A maceração foi realizada pelo método de Jeffrey (Freund, 1970). Os cortes anatômicos foram tingidos com acridina-vermelha, crisoidina e azul-de-astra (Dujardin, 1964); o macerado, apenas com safranina (1\%). A montagem de lâminas permanentes foi feita com Entellan.

A descrição baseou-se nas recomendações do IAWA Committee (Wheeler et al., 1989). No caso da percentagem dos tecidos, foram realizadas 600 determinações ao acaso, com auxílio de contador de laboratório, conforme proposto por Marchiori (1980). A abundância de poros foi obtida a partir de um quadrado de área conhecida, superposto a fotomicrografias de seções transversais da madeira.

As medições foram realizadas em microscópio Carl Zeiss, no Laboratório de Anatomia da Madeira da Universidade Federal de Santa Maria. Nas características quantitativas, os números entre parênteses equivalem aos valores mínimos e máximos observados; o valor que acompanha a média é o desvio padrão. As fotomi- crografias foram tomadas em microscópio Olympus CX40, equipado com câmera digital Olympus Camedia c3000, no Laboratório de Anatomia da Madeira da Universidade Federal do Paraná.

\section{DESCRIÇÃO ANATÔMICA}

Anéis de crescimento: distintos, marcados por estreita camada de fibras radialmente achatadas (cerca de 4 células) no lenho tardio e poros de maior diâmetro no lenho inicial (Figura 1A,B).

Vasos: numerosos $(31 \pm 10,3(20-44)$ poros $/ \mathrm{mm}^{2}$ ), ocupando $18 \pm 5,4 \%$ do volume da madeira. Porosidade semi-difusa. Poros solitários e em múltiplos radiais de 2-4, circulares ou ovais $(107 \pm 23,7(62,5-145) \mu \mathrm{m})$ e de paredes finas $(3,8 \pm 0,8(2,5-5) \mu \mathrm{m})$ (Figura 1A,B). Elementos vasculares curtos ( $299 \pm 104,3$ (150 -560) $\mu \mathrm{m}$ ), com placas de perfuração simples, transversais e oblíquas, geralmente sem apêndices (Figura 1E,F). Pontoações intervasculares pequenas $(5,8 \pm 1,2(4,1-8,2) \mu \mathrm{m})$, alternas, circulares, por vezes coalescentes. Abertura em fenda inclusa, ornamentada (Figura 1D,F). Espessamentos espiralados, ausentes. Conteúdos, frequentes no lenho tardio (Figura 1A,B).

Parênquima axial: ocupando $8 \pm 1,3 \%$ do volume da madeira; em arranjo paratraquealescasso (Figura 1B). Séries parenquimáticas de $286 \pm 69(150-442) \mu \mathrm{m}$ de altura e 2-4 células.

Raios: numerosos (7 $\pm 1,1(6-9)$ raios $/ \mathrm{mm})$, heterogêneos, com 1-3 células de largura, ocupando $16,5 \pm 3,2 \%$ do volume da madeira (Figura $1 \mathrm{E}, \mathrm{F})$. Os multisseriados, predominantes, de $764 \pm 451(170-2200) \mu \mathrm{m}$ e $30-116$ células de altura, compostos de células procumbentes no corpo central, e 1-2 fileiras marginais de células eretas e/ou quadradas (Figura 1C,D). Os unisseriados, de $143 \pm 47,1(60-240) \mu \mathrm{m}$ e 5 17 células de altura. Raios agregados, células radiais de paredes disjuntas, células perfuradas, células envolventes e conteúdos, ausentes.

Fibras: libriformes; curtas (684 $\pm 183,3$ (400 - 900) $\mu \mathrm{m})$, de $21 \pm 5,6(12,5-32,5) \mu \mathrm{m}$ de largura e paredes finas a espessas 4,6 $\pm 0,9(3,7$ 

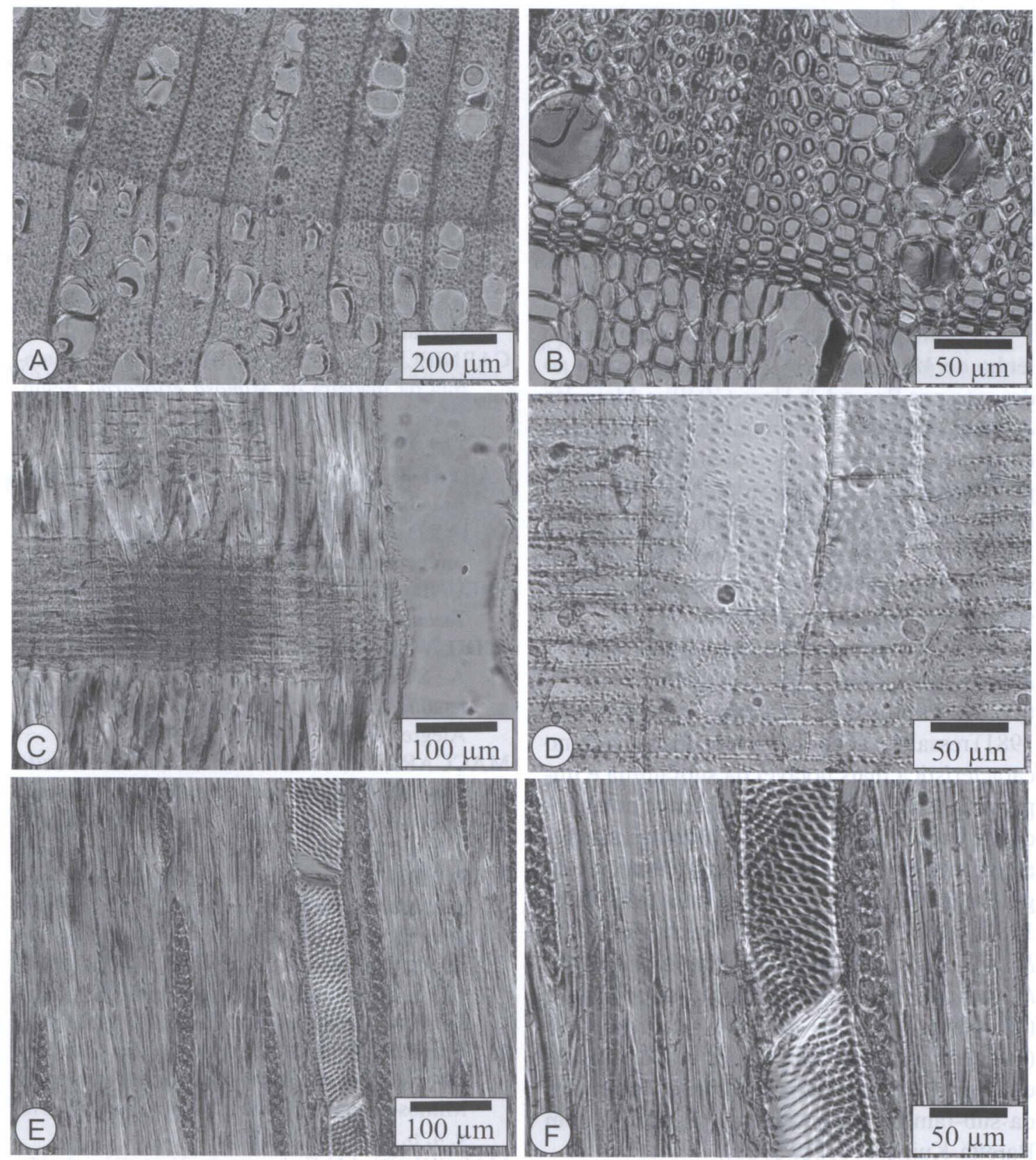

FIGURA 1 - Aspectos anatômicos do lenho de Mimosa flocculosa Burkart. A - Seção transversal, mostrando porosidade semi-difusa; poros em curtos múltiplos radiais e solitários; e limite do anel de crescimento, com fibras espessas no lenho tardio e fibras menos espessas no lenho inicial. B - Mesma seção, em maior aumento, com poros com conteúdos; parênquima paratraqueal-escasso, e limite do anel de crescimento. C - Raios heterogêneos, em seção longitudinal radial, com células procumbentes, no corpo central, e células eretas e/ou quadradas nas margens, e elemento vascular. D - Seção longitudinal radial, em maior aumento, mostrando células procumbentes de raio e elemento vascular com pontoações alternas. E - Vista geral da seção longitudinal tangencial, com destaque para raios multisseriados, e elemento vascular com pontoações alternas e placas de perfuração quase transversais. F - Vasos com pontoações intervasculares alternas, por vezes coalescentes, placa de perfuração perpendicular, e raios bisseriados (seção longitudinal tangencial). 
- 6) $\mu \mathrm{m}$, ocupando $18 \pm 5,4 \%$ do volume da madeira (Figura 1B). Fibras gelatinosas, espessamentos espiralados e traqueídeos, ausentes.

Outros caracteres: variantes cambiais, tubos laticíferos e taniníferos, canais intercelulares, células oleíferas, células mucilaginosas, estratificação, máculas medulares e cristais, ausentes.

\section{ANÁLISE DA ESTRUTURAANATÔMICA}

As principais características anatômicas do lenho de Mimosa flocculosa correspondem ao descrito por Record \& Hess (1949) e Metcalfe \& Chalk (1972) para a família Leguminosae (Fabaceae): elementos vasculares curtos; pontoações intervasculares alternas, ornamentadas; parênquima paratraqueal; e fibras libriformes. Estes mesmos caracteres, por sua vez, atestam elevada especialização ao xilema secundário (Marchiori \& Muñiz, 1997a).

O tecido radial heterogêneo, observado em Mimosa flocculosa, foge ao padrão característico das Mimosoídeas. Baretta-Kuipers (1980, 1981) ressalta a homogeneidade dos raios como característica mais notável da subfamília e importante tendência evolutiva. Cumpre notar, todavia, que a presença de raios heterogêneos foi anteriormente citada para diversas espécies do gênero, incluindo Mimosa scabrella (Marchiori 1980, 1995), M. daleoides (Marchiori, 1982), M. eriocarpa (Carnieletto \& Marchiori, 1993), M. incana (Marchiori, 1996b), M. pilulifera (Marchiori \& Muñiz, 1997a), e M. micropteris (Pereira et al., 2013). A ausência de estratificação, por sua vez, é caráter indicativo da sub-família Mimosoideae, de acordo com Baretta-Kuipers (1980, 1981).

\section{REFERÊNCIAS BIBLIOGRÁFICAS}

BARETTA-KUIPERS,T. The wood structure of leguminous tribes: their classification by ray and parenchyma features. For. Prod. Abstr., v.3, n.8, p.1-784, 1980.
BARETTA-KUIPERS,T. Wood anatomy of Leguminosae: its relevance to Taxonomy. In: POLHILL, R. M. \& RAVEN, P.H. Advances in Legume Systematics. 1981. p. 677-715.

BARNEBY, R.C. Sensitivae Censitae. A description of the genus Mimosa Linnaeus (Mimosaceae) in the New World. Memoirs of the New York Botanical Garden, v. 65, p. 1-835, 1991.

BURGER, L.M.; RICHTER, H.G. Anatomia da Madeira. São Paulo: Ed. Nobel, 1991. 154 p.

BURKART, A. Leguminosas Mimosoideas. In: REITZ, P.R. Flora Ilustrada Catarinense. Itajaí: Herbário Barbosa Rodrigues, 1979. 299 p.

CARNIELETTO, C.; MARCHIORI, J.N.C. Anatomia da madeira de Mimosa eriocarpa Benth. Ciência Florestal, Santa Maria, v. 3, n. 1, p. $107-$ 120, 1993.

CARVALHO, P.E.R. Espécies Arbóreas Brasileiras. Brasília: Embrapa, 2003. 1040 p.

DUJARDIN, E.P. Eine neue Holz-Zellulosenfaerbung. Mikrokosmos, n. 53, p. 94, 1964.

FREUND, H. Handbuch der Mikroskopie in der Technik. Frankfurt: Umsham Verlag, 1970.375 p. JUDD, W. S.; CAMPBELL, C. S.; KELLOGG, E. A.; STEVENS, P. F.; DONOGHUE, M. J. Sistemática vegetal: um enfoque filogenético. Porto Alegre: Artmed, 2009. p. 371-377.

MACCARI, A.; MARCHIORI, J.N.C. Estudo anatômico do xilema secundário de Mimosa sparsa Benth. Ciência Florestal, Santa Maria, v. 4, p. 145-155, 1994.

MARCHIORI, J.N.C. Estudo anatômico do xilema secundário e da casca de algumas espécies dos gêneros Acacia e Mimosa, nativas no Estado do Rio Grande do Sul. Curitiba: UFPR, 1980. 185 f. Dissertação (Mestrado em Engenharia Florestal - Universidade Federal do Paraná).

MARCHIORI, J.N.C. A estrutura do xilema secundário de Mimosa daleoides Benth. (Leguminosae Mimosoideae). Ciência e Natura, Santa Maria, v. 4, p. 107-113, 1982.

MARCHIORI, J.N.C. Anatomia da madeira de $\mathrm{Mi}$ mosa cruenta Benth. (Leguminosae Mimosoideae). Ciência e Natura, Santa Maria, v. 7, p. 73-81, 1985.

MARCHIORI, J.N.C. Anatomia da madeira e casca do maricá, Mimosa bimucronata (DC.) O. Kuntze. Ciência Florestal, Santa Maria, v. 3, n. 1, p. 85-106, 1993. 
MARCHIORI, J.N.C. Anatomia da madeira e casca da bracatinga, Mimosa scabrella Benth. Ciência e Natura, Santa Maria, v. 17, p. 115-132, 1995.

MARCHIORI, J.N.C. Anatomia do xilema secundário de Mimosa berroi Burk. Ciência e Natura, Santa Maria, v. 18, p. 117-129, 1996a.

MARCHIORI, J.N.C. Anatomia do xilema secundário de Mimosa incana (Spreng.) Benth. Ciência Florestal, Santa Maria, v. 6, n. 1, p. 53-63, 1996b.

MARCHIORI, J.N.C. Anatomia do xilema secundário de Mimosa uruguensis Hook. et Arn. Ciência e Natura, Santa Maria, v. 18, p. 103-115, 1996c.

MARCHIORI, J.N.C.; MUÑIZ, G.I.B. de. Anatomia do xilema secundário de Mimosa pilulifera Benth. Ciência Florestal, Santa Maria, v. 6, n. 1, p. 65-75, 1997a.

MARCHIORI, J.N.C.; MUÑIZ, G.I.B. de. Estudo anatômico do xilema secundário de Mimosa trachycarpa Benth. Ciência Rural, Santa Maria, v. 27, n. 2, p. 223-228, 1997 b.
MARCHIORI, J. N. C. Dendrologia das Angiospermas: Leguminosas. Santa Maria: UFSM. 2007. 199 p.

METCALFE, C.R.; CHALK, L. Anatomy of the Dicotyledons. Oxford: Clarendon Press, 1972. p. 476-487.

PEREIRA, A. C; SIEGLOCH, A. M.; MARCHIORI, J. N. C. Anatomia do lenho de Mimosa micropteris Benth. Balduinia. n. 40, p. 18-22, 2013.

RECORD, S.J.; HESS, R.W. Timbers of the New World. New Haven: Yale University Press, 1949. $640 \mathrm{p}$.

SOUZA, V. C.; LORENZI, H. Botânica Sistemáti$c a$ : guia ilustrado para identificação das famílias de Angiospermas da flora brasileira, baseado em APG II. Nova Odessa: Instituto Plantarum, 2012. p. 381-422.

WHEELER, E.A.; BAAS, P.; GASSON, P.E. IAWA list of microscopic features for hardwood identification. IAWA Bulletin, v.10, n. 3, p. 218359, 1989. 